In der Rubrik „Literatur kompakt" werden die wichtigsten Originalarbeiten aus der internationalen Fachliteratur referiert.

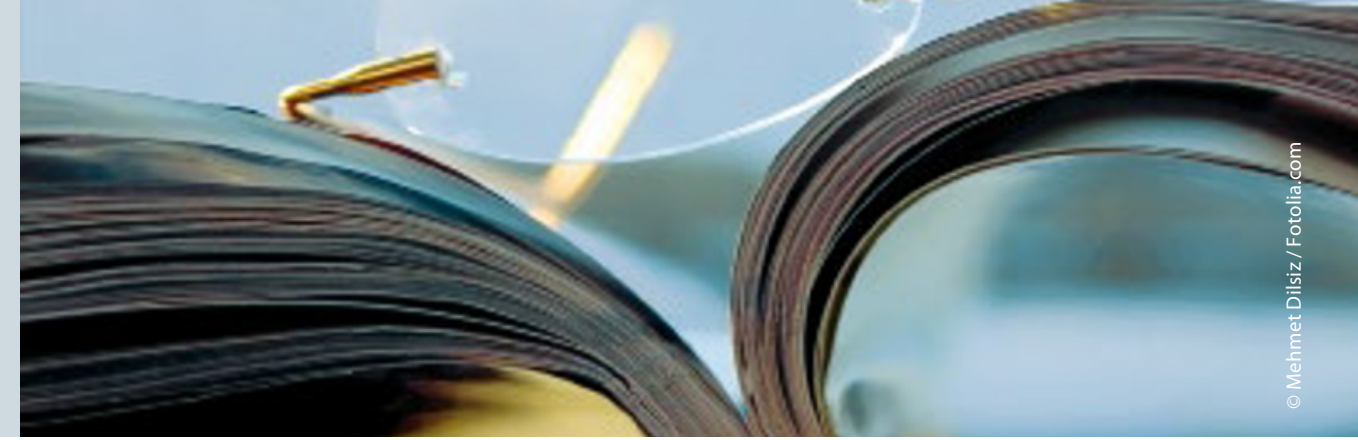

\title{
Monoklonaler Anti-CGRP-Antikörper bei hochfrequenter episodischer Migräne wirksam
}

\begin{abstract}
Nach den Daten einer Phase-II-Studie ist der monoklonale Anti-CGRPAntikörper TEV-48125 in der Prophylaxe der hochfrequenten episodischen Migräne wirksam. Nun gilt es, die Ergebnisse durch eine große Phase-IIIStudie zu bestätigen.
\end{abstract}

W ährend Migräneattacken wird das Calcitonin gene-related peptide (CGRP) ausgeschüttet, das als ein potenter Vasodilatator wirkt.

CGRP hat offenbar eine Vielzahl von biologischen Wirkungen im zentralen Nervensystem, die bis heute allerdings noch nicht ausreichend geklärt sind. Zur Behandlung von Migräneattacken wurden CGRP-Antagonisten entwickelt, die sich zwar als wirksam erwiesen, dedoch musste die weitere Entwicklung von CGRP-Antagonisten aufgrund von hepatotoxischen Nebenwirkungen eingestellt werden.

Der nächste Ansatz zur Migräneprophylaxe war die Entwicklung von monoklonalen humanisierten Antikörpern gegen CGRP. Ein solcher Antikörper ist TEV-48125.

Für die multizentrische randomisierte doppelblinde placebokontrollierte Phase-IIb-Studie wurden Patienten mit acht bis 14 Migränetagen pro Monat rekrutiert. Nach einer 28-tägigen Run-inPhase erhielten die Patienten alle vier Wochen subkutan $225 \mathrm{mg}$ oder $675 \mathrm{mg}$ TEV-48125 oder Placebo. Die Kopfschmerzhäufigkeit wurde in einem elektronischen Tagebuch erfasst. Der primäre Endpunkt war die Reduktion der Migränetage zwischen Baseline und den Wochen 9-12. Der sekundäre End- punkt war die Reduktion der Kopfschmerztage.

In die Studie wurden 297 Teilnehmer eingeschlossen. Von diesen erhielten 104 Placebo, 95 die niedrige und 96 die hohe Dosis von TEV-48125. Die Patienten waren im Mittel 41 Jahre alt und $90 \%$ waren Frauen. Die mittlere Zahl der Migränetage pro Monat betrug elf, die mittlere Zahl der Kopfschmerztage pro Monat 12,5. An zehn Tagen pro Monat wurden Medikamente eingenommen, davon an 8,4 Tagen Triptane. Die Abnahme der Migränetage zwischen Baseline und Woche $9-12$ betrug 3,46 Tage für Placebo, 6,72 Tage für die niedrige Dosis und 6,09 Tage für die hohe Dosis von TEV-48125. Diese Unterschiede waren statistisch signifikant. Die Differenz der Kopfschmerztage betrug 2,63 Tage zwischen Placebo und der niedrigen Dosis und 2,58 Tage zwischen Placebo und der hohen Dosis von TEV-48125, auch diese Unterschiede waren signifikant. Die Zahl der berichteten Nebenwirkungen war zwischen den drei Therapiegruppen nicht unterschiedlich.

Fazit: Die Gabe von $225 \mathrm{mg}$ oder $675 \mathrm{mg}$ TEV-48125 alle 28 Tage als subkutane Injektion ist sicher und wird gut toleriert. Die Substanz ist wirksam in der
Migräneprophylaxe bei häufiger episodischer Migräne.

Bigal ME, Dodick DW, Rapoport AM et al. Safety, tolerability, and efficacy of TEV-48125 for preventive treatment of high-frequency episodic migraine: a multicentre, randomised, doubleblind, placebo-controlled, phase $2 b$ study. Lancet Neurol 2015; 14: 1081 -90

\section{Kommentar}

Es gibt jetzt vier neue CGRP-Antikörper oder Antikörper gegen den CGRP-Rezeptor, die alle in Phase-II-Studien besser wirksam sind als Placebo. Besonders hervorzuheben ist das gute Nebenwirkungsprofil, das sich nicht von Placebo unterscheidet. Soweit bisher eine Beurteilung möglich ist, ist die Entwicklung von Antikörpern gegen den therapeutischen Antikörper kein größeres Problem. Allerdings liegen für alle Substanzen bisher keine Langzeitbehandlungsraten vor. Der nächste Schritt in der Entwicklung von TEV-48125 wird sein, die Ergebnisse dieser Studie durch eine große Phase-IIIStudie zu bestätigen.

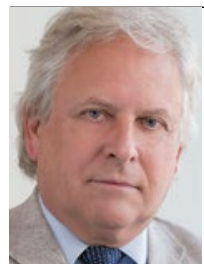

Prof. Dr. med. HansChristoph Diener, Essen Direktor der Klinik für Neurologie, Universitätsklinikum Essen, E-Mail: h.diener@uni-essen.de 